\section{Thermaticity, abstractness, and the long-term recall of connected discourse}

\author{
R. P. PHILIPCHALK* \\ University of Western Ontario, London, Ont., Canada
}

Ss were given four study test trials on either concrete or abstract paragraphs presented in either thematic or nonthematic order. Effects of thematicity and abstractness were observed both after the fourth training trial and 2 weeks later Thematicity was effective only when the paragraph was concrete, suggesting that recall of concrete material involves reconstruction from a surrogate structure involving conrete imagery.

Yuille \& Paivio (1969) have suggested that meaning plays a greater role in memory for concrete than for abstract material. Following Pompi \& Lachman (1967), they hypothesized that recall of connected discourse involves reconstruction from a surrogate structure which is more likely to be generated when the material is concrete than when it is abstract. In line with these considerations, they found that recall of concrete material was facilitated by thematic presentation, while recall of abstract material was not. Analysis of error scores revealed that a greater proportion of errors was theme-related for Ss who were presented with the material in thematic rather than in random order, again substantiating the hypothesis that thematically meaningful discourse generates surrogate structures which retain the essential theme of a pissage and from which the passage may be reconstructed.

The present study was designed as a partial replication and extension of the Yuille \& Paivio (1969) findings. Essentially the same materials and procedure were used as in the Yuille and Paivio study, with the addition that delayed as well as immediate recall was investigated. Delayed recall was examined as a further test of the hypothesis that meaning was responsible for the differences found by Yuille and Paivio. Sachs (1967a, b) and Begg (1971), in examining the independence of meaning and wording in memory, showed that memory for wording dropped sharply as a function of interpolated material and time while memory for meaning remained high.

Therefore, it was expected that the

*This research was supported by the University of Western Ontario Research Fund. Thanks are due to Al Paivio for helpful criticisms at all stages of the research. Requests for reprints should be sent to R. P. Philipchalk, Department of Psychology, St. Thomas University, Fredericton. N.B., Canada. interaction of order with abstractness found by Yuille and Paivio (superior recall for thematic presentation over random presentation for a concrete passage and no difference for an abstract passage), presumably based on the benefit of meaning retention by a surrogate structure rather than superior retention of wording or syntax, would hold up after a relatively long delay. If the interaction was not found after a delay, it would suggest that the Yuille and Paivio findings were produced by characteristics of the thematic concrete passage, which made the wording easier to retain, rather than by reconstruction from a central theme or meaning. Therefore, replication of Yuille and Paivio's findings in immediate recall, and particularly at the delay period, would add further support to the hypothesis that recall of connected discourse involves reconstruction from a surrogate structure that includes imagery and is more likely to be generated from a concrete than from an abstract passage.

\section{SUBJECTS}

The Ss were 65 students of introductory psychology. They were assigned randomly to one of four thematicity combined with two levels of abstractness). Group size for training trials and immediate recall ranged from 15 to 17 . However, because not all Ss showed up for the delayed recall test, group size after 2 weeks' delay ranged from 7 to 12 .

\section{MATERIALS}

Two of the six 79-word paragraphs described by Yuille \& Paivio (1969) were used. The concrete paragraph described a battle scene and was the same one used by Pompi \& Lachman (1967). The abstract paragraph was constructed by Yuille and Paivio and was as similar to the concrete one as possible in all aspects except abstractness (i.e., theme, length, syntactical category and frequency of words, emotionality, and meaningfulness). The mean rated experimental conditions ( $t$ wo levels of concreteness and specificity of the abstract passage $(2.50$ and 1.83 , respectively) was less than half that of the concrete passage (6.83 and 6.50).

Each word of a paragraph was typed on a blank card, approximately $21 / 2 \times 4$ in. One-half of the card decks for each paragraph were shuffled to give a random order of presentation. The other half remained in (thematic) English order.

\section{PROCEDURE}

All Ss were tested in a single group for immediate learning and recall as well as after 2 weeks' delay. Each $\mathrm{S}$ was given one deck of 80 cards, the top card being a $\mathrm{S}$ identification card. Each $S$ was also given a sheet of mimeographed instructions and a four-page response booklet. The instructions were the same for all $\mathrm{Ss}$, except that those receiving the material in thematic order were told that the words formed a short story. Those Ss receiving the material in random order were told that the words were randomly drawn from the dictionary. The instructions explained that they were to flip through the cards in time with tape-recorded "clicks" at $1 \mathrm{sec} / \mathrm{card}$. Following the last card on each of four training trials, Ss were given $4 \mathrm{~min}$ to recall, in any order, as many of the words as they could. Two weeks later, Ss were again given a 4-min free recall period. They had not been warned of the delayed recall test, and subsequent discussion indicated that they had not expected it.

\section{RESULTS}

Mean number of words correctly recalled (ignoring inflectional suffixes, cf. Pompi \& Lachman, 1967) is presented in Table 1 . These scores were analyzed by means of a 2 by 2 by 4 (Thematicity by Abstractness by Trials) analysis of variance for study test trials and a 2 by 2 (Thematicity by Abstractness) analysis of variance for the 2-week delay condition.

As can be seen in Table 1 , the main effects were qualified by a significant Thematicity by Abstractness interaction $[F(1,61)=9.99, p<.01]$, which reflects the fact that thematic

Table 1.

Mean Correct Recall After the Fourth Learning Trial and 2 Weeks Later as a Function of Order of Presentation and Abstractness of Material

\begin{tabular}{lccccc}
\hline & \multicolumn{2}{c}{ Concrete } & & \multicolumn{2}{c}{ Abstract } \\
\cline { 2 - 5 } \cline { 5 - 6 } & Mean SD & & Mean & SD \\
\hline Thematic & \multicolumn{3}{c}{ Immediate } & Recall \\
Random & 58.0 & 10.4 & 33.8 & 7.0 \\
& 39.9 & 8.8 & & 31.9 & 9.4 \\
Thematic & & Delayed & Recall \\
Random & 24.5 & 6.6 & 14.2 & 4.5 \\
& 14.0 & 4.0 & 11.8 & 7.4 \\
\hline
\end{tabular}


presentation was effective only with concrete material.

Recall after 2 weeks was approximately one-half of recall after the last learning trial. The interaction of Thematicity by Concreteness was also significant at the 2-week delay $[F(1,37)=4.58, \quad p<.05]$. These results are also presented in Table 1 , where again it can be seen that thematic presentation led to improved recall only with concrete material.

The proportion of errors that were theme-related was also examined. The pattern of this result essentially mirrored that of the free recall data.

\section{DISCUSSION}

The positive effect on recall found for thematic presentation of concrete material indicates that concrete connected discourse has a unique property not possessed by either concrete or abstract material in random order or by abstract connected discourse. Pompi \& Lachman (1967) have suggested that this property is the ability to generate a "surrogate structure" retaining the central theme or meaning of the passage and from which the passage may be reconstructed. The present results support this hypothesis both in the superior recall and in the theme-relatedness of errors observed for concrete connected discourse.

The relationship of thematicity to the hypothesized surrogate structure is fairly straightforward (a thematic presentation generates a surrogate structure, while a random presentation does not). However, the relationship of abstractness to thematicity is not as clear. Pompi \& Lachman (1967) suggested that a surrogate structure was less likely to be generated by abstract than by concrete discourse. The findings of Yuille \& Paivio (1969) and those of the present study support this hypothesis in that a positive effect of thematicity on recall was found only for concrete material. However, alternatively, these results could be interpreted to mean that, although the surrogate structure generated by abstract material is also used as the basis of recall, it contributes no positive effect to the amount recalled. Nevertheless, the evidence to date provides no support for this alternative.

\section{REFERENCES}

BEGG, I Recognition memory for sentence meaning and wording. Journal of Verbal Learning \& Verbal Behavior, 1971, 10, $176-181$.

POMPI, K. F., \& LACHMAN, R. Surrogate processes in the short-term retention of connected discourse. Journal of Experimental Psychology, 1967, 75, 143-150.

SACHS, J. S. Recognition memory for syntactic and semantic aspects of connected discourse. Perception \& Psychophysics, 1967a, 2(9), 437-442.

SACHS, J. S. Recognition of semantic, syntactic, and lexical changes in sentences. Paper presented at Psychonomic Society, October $1967 \mathrm{~b}$.

YUILLE, J. C., \& PAIVIO, A. Abstractness and the recall of connected discourse. Journal of Experimental Psychology, $1969,82,467-471$ 